\title{
Piotr Mackiewicz
}

Dr hab. inż.

Politechnika Wrocławska, Zakład Dróg I Lotnisk

piotr.mackiewicz@pwr.edu.pl

\section{Antoni Szydło}

Prof. dr hab. inż.

Politechnika Wrocławska, Zakład Dróg I Lotnisk

antoni.szydlo@pwr.edu.pl

DOI: 10.35117/A_ENG_18_11_10

\section{Analysis of the impact of concrete pavement finishing technologies on selected exploitation traits}

\begin{abstract}
We studied various technologies of finishing the upper layers of the concrete pavements. The analyses were made on the basis of own research on selected sections of motorway and express roads with a concrete surface in Poland. On this basis, the variability of equality and texture was determined depending on different types of structures, finishing methods and operational periods. It was found that the change of construction technology and the type of construction significantly influence the change of equality, while the technology of finishing the upper surface influences the texture. The best equality was obtained for the nondilatation pavements with continuous reinforcement. It was shown that the texture indicator is strongly dependent on the pavement exploitation. In addition, an assessment of the impact of equality and texture on the noise level in the vehicle's cabin was carried out.
\end{abstract}

Keywords: Texture; Roughness; Concrete Pavement; Continuously Reinforced (no joints) Pavement; IRI; MPD

\section{Introduction}

The interest in concrete pavements in Poland increased at the end of the last century. Until then, concrete pavements were implemented sporadically on short sections, mainly at airports, parking lots and company roads. It was only in 1995 that the first longer sections were constructed on the A4 motorway, intended for heavy traffic. At a later stage, the section on A2 (2012) was implemented in the so-called of the discovered aggregate technology, followed by the S8 route (2015). Two experimental sections for A2 (2012) and A4 (2004) were made in the non-dilatation technology. In addition, currently, roads are realized on express roads: S7, S8, S17, S61, and A1 motorway. In addition to surfaces made in new technologies, there are also older sections with a concrete surface, such as DK50 from 2002, and the A18 highway from the 1940s.

Currently, in the world of road engineering for low traffic loads, surfaces: unarmed and uneven. For larger loads, dowel and anchored surfaces (with transverse gaps) and surfaces with continuous reinforcement without cross gaps are used.

An important problem in obtaining proper use of concrete pavements is the appropriate finish of the upper surface of the concrete slab, which is associated with anti-slip features and noisiness.

The aim of the article is to identify equality (expressed in the International Roughness Index, IRI), macrotexture (expressed in the Mean Profile Depth Index, MPD), various concrete surfaces in Poland depending on: the way the upper surface is finished, the lifetime 
of the gaps. These parameters are important from the point of view of traffic safety and the environment because they affect the friction coefficients of the wheel and road surface as well as the noise level generated by the moving wheels on the surface.

\section{An overview of experiences}

The first structural analyzes for concrete pavements were carried out already in the '70s of the last century in connection with road accidents [10]. The Federal Highway Administration (FHWA) has pre-punched the transverse grooving of concrete pavements and indicated the requirements for adapting to different speeds. In the next stage, longitudinal grooves were introduced in the form of pulling the jute mat and brushing.

Other extensive conclusions from the research were compiled in a study from 1996 [20]. Based on the results, it was found that the surface finish has a significant impact not only on the friction parameters, but also on the noise frequency values, but without changing the general noise level.

The report [24] containing extensive research on 57 research sections in Colorado included analysis of texture measurements at the mean profile depth (MPD - Mean Profile Depth) and estimated texture depth (ETD - Estimated Texture Depth). Initial measurements were also carried out on a two-kilometer length of the "uncovered aggregate" surface. At a later stage of the work, textures were sought for concrete pavements that would provide good tacking characteristics, as well as retaining their acoustic properties, unchanged over time. Various grinding techniques were analyzed (Fig. 1, [29], [8]). Significant reduction of noise level for the new technology in the longitudinal direction called Next Generation Concrete (NGCS) [5] was indicated. This technology is a combination of already known finishing techniques: "Grinding" and "Grooving."

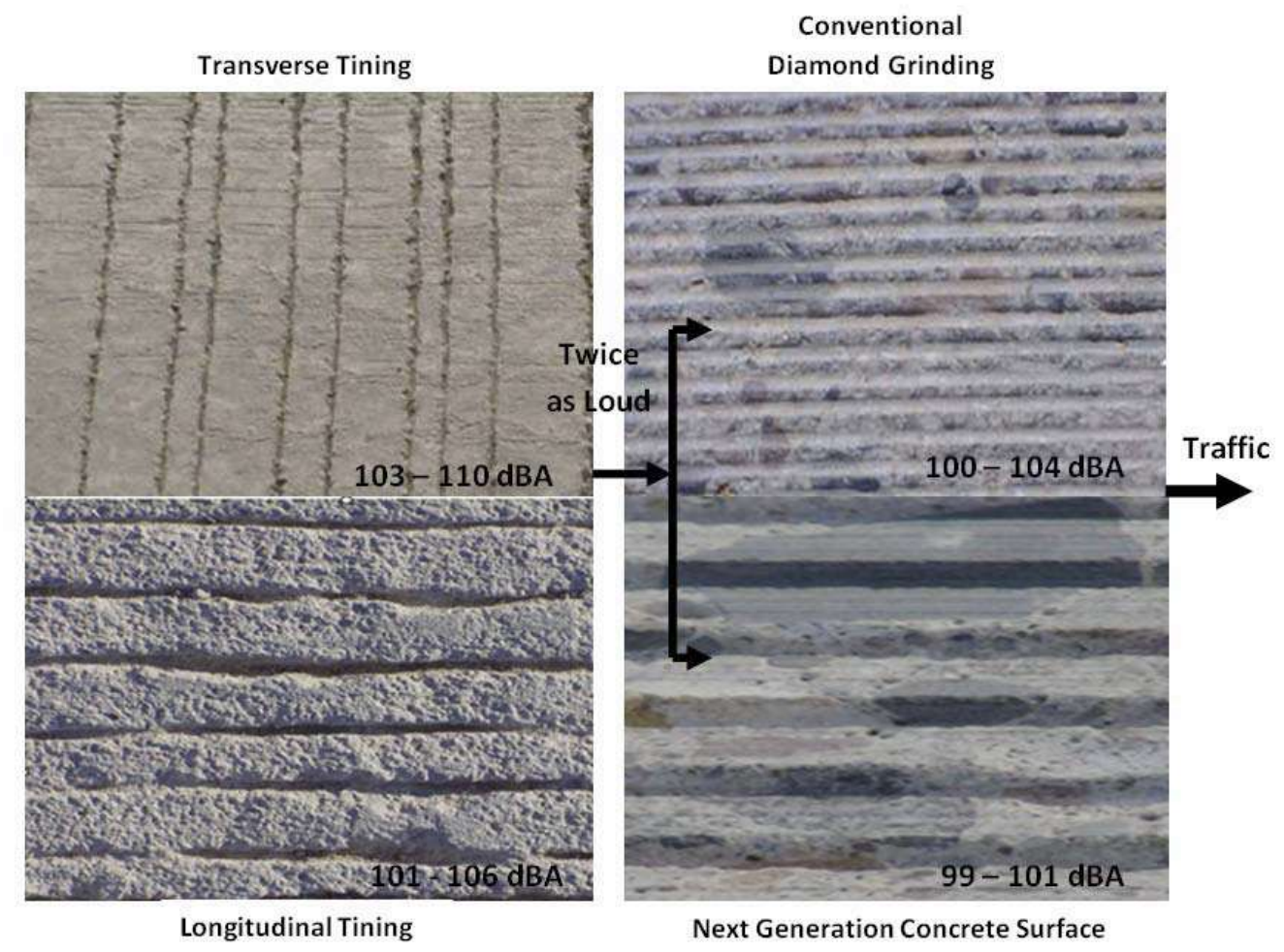

1. Different surface structures and noise levels according to [29], [8] 
In the scope of other works, the advantages of drawn jute matting [6], [12], [27], random structures [19] and concrete porous surfaces [25] were also analyzed. Many studies contain technologies and guidelines for the implementation of various surface textures [1], [16], [17], [11]. Analyzes were also carried out in the scope of measuring and identifying equality and textures using various methods [4], [3], [21], [18], [15] indicating good correlations between them.

Particular attention was paid to the special texturing of concrete surfaces in Europe. Although research on structures with "discovered aggregate" was conducted earlier in America, more pavements in this technology were implemented in Europe [7], [30], [22]. The tests have clearly confirmed the effectiveness of this technology in reducing the noise level while ensuring the required wheel friction conditions with surfaces similar to SMA. Similar observations regarding similar noise of concrete pavements for susceptible surfaces with SMA wear layers confirm many years of national research [14], [23], [13].

Based on the literature review, it is stated that the technology of finishing the upper surface of concrete pavements has different traditions in many countries. Currently, in Poland, there are no explicit guidelines and recommendations in this area. Due to the fact that the texture significantly affects both traffic safety and noise level generated, an attempt was made to carry out comprehensive tests and analyzes for concrete pavements. The article presents the results of measurements of equality and macrotexture made for various surfaces made in Poland. The dependence of the above-mentioned parameters on the technology of pavement construction, the type of top surface finish, the impact of environmental factors as well as the sound level recorded in the vehicle cabin has been established.

\section{Characteristics of research sections and measuring technology}

On the basis of selected locations of motorways and expressways in Poland, detailed measurements of texture and evenness of concrete pavements were carried out, taking into account different construction technologies and finishing of the upper surface (Fig. 2). 


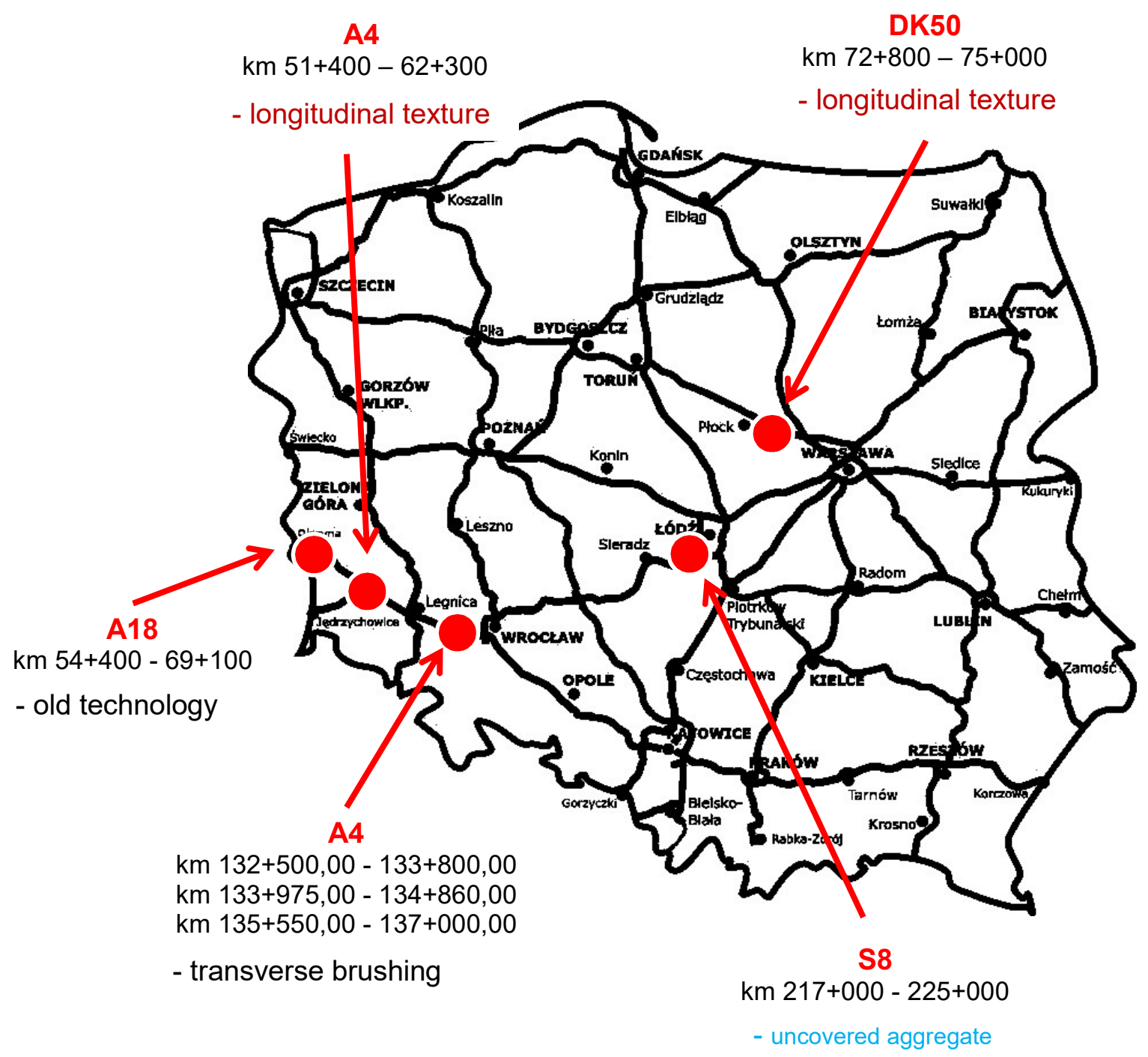

2. Location of measuring sections of concrete surfaces

In terms of the section of the A4 motorway $(\mathrm{km} 132+500-137+000)$, different types of concrete surfaces were tested: paved surface (with transverse gaps) on the foundation of aggregate, surface with continuous reinforcement (without transverse gaps), paved surface (with transverse gaps) on the foundation of lean concrete. The northern carriageway was commissioned in 2005, and the southern carriageway in 2000. The transverse gaps were filled with profiles. The upper surface of the surface has been finished with transverse brushing (Fig. 3). 

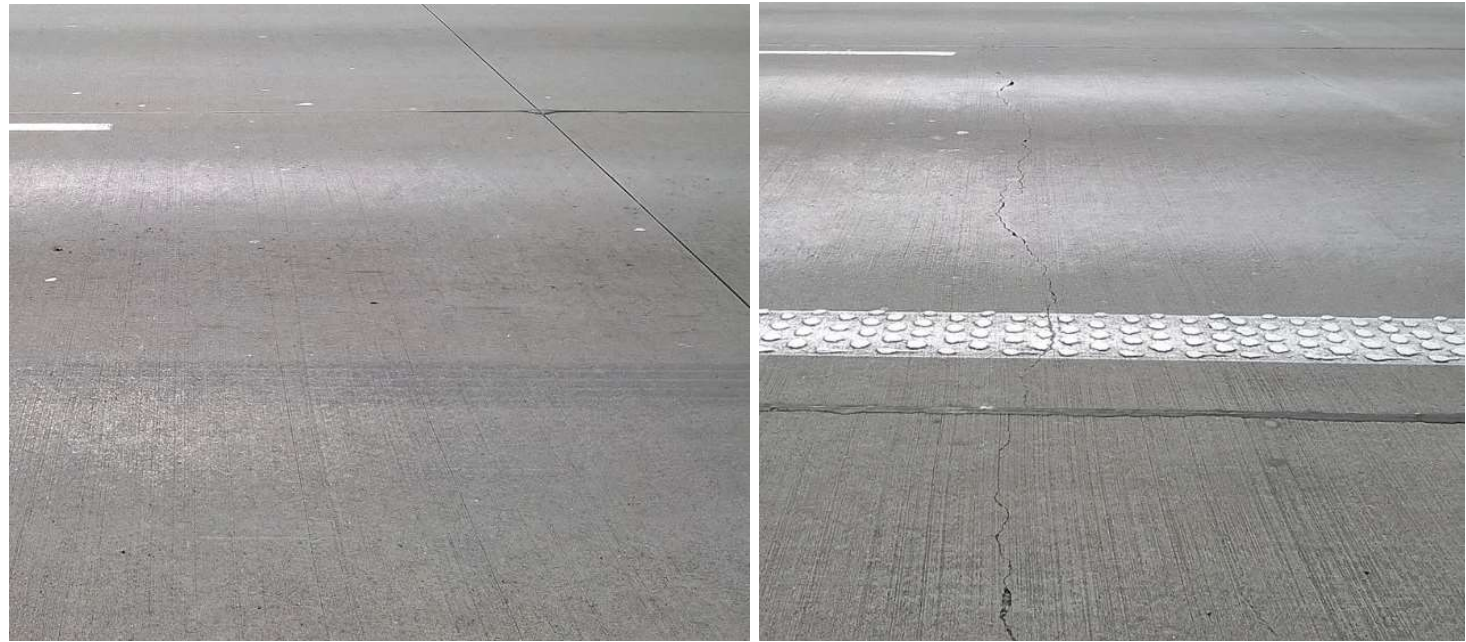

3. The A4 motorway - paved surface (left) and continuous reinforcement (on the right)

On the S8 expressway (the year of putting into operation 2015), the surface of the aggregate technology was analyzed on a section of eight kilometers (Figure 4). The pavement is made of concrete slabs with transverse gaps on the foundation of lean concrete.
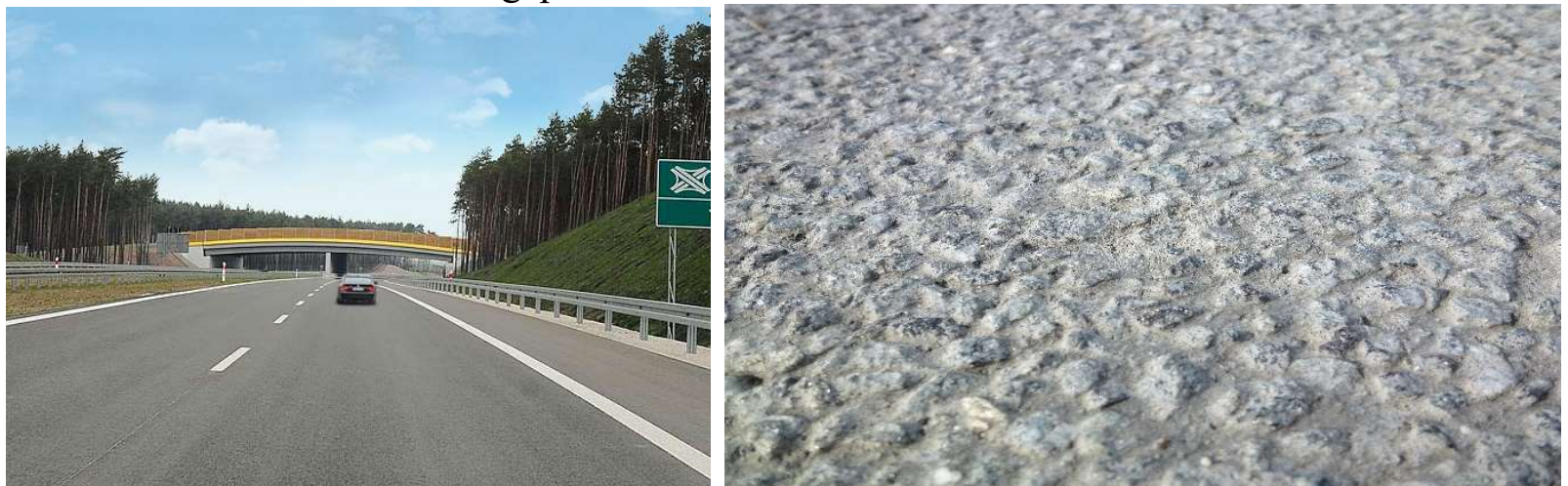

4. The S8 expressway - "discovered aggregate" technology

Additional measurements were carried out on the A4 motorway section $51+400-62+300$ in longitudinal texturing technology (jute mat). In this section, the concrete surface comes from 1995.

A section of the A18 km $54+400$ motorway $-69+100$ motorway was analyzed separately. In this section, there is an old concrete surface (1940) with a low level of equality and significantly damaged dilatation.

Within the scope of research and requirements [2], [26], [28] using the laser profilograph, the IRI (International Roughness Index) parameter was determined and the texture expressed by the MPD index (Mean Profile Depth): the right wheel trace. These parameters are used in the DSN system that identifies the surface condition in Poland [9].

\section{Analysis of test results depending on the technology of pavement construction}

Most of the analyzed concrete surfaces were built in technology with transverse gaps. However, the episode in the non-dilatation technology was realized as a concrete surface with continuous reinforcement. They include A4 section on the northern roadway $\mathrm{km} 133+975-$ $134+860$.

It is generally believed [29] that cross-connections of panels can contribute to a general increase in noise in two cases. The first situation occurs when there is not enough load 
transfer between the plates, then the vehicle tires will cause a "slam". When plate deflections exceed 4-5 mm, this can be noticeable and uncomfortable, especially in the case of noise levels inside the vehicle. The second situation concerns too wide gap width and its quality of filling. The wider the gap and the poorly maintained, the greater the noise level.

Fig. 5 presents the results of measurements of the IRI indicator value on the tested sections of concrete pavement.

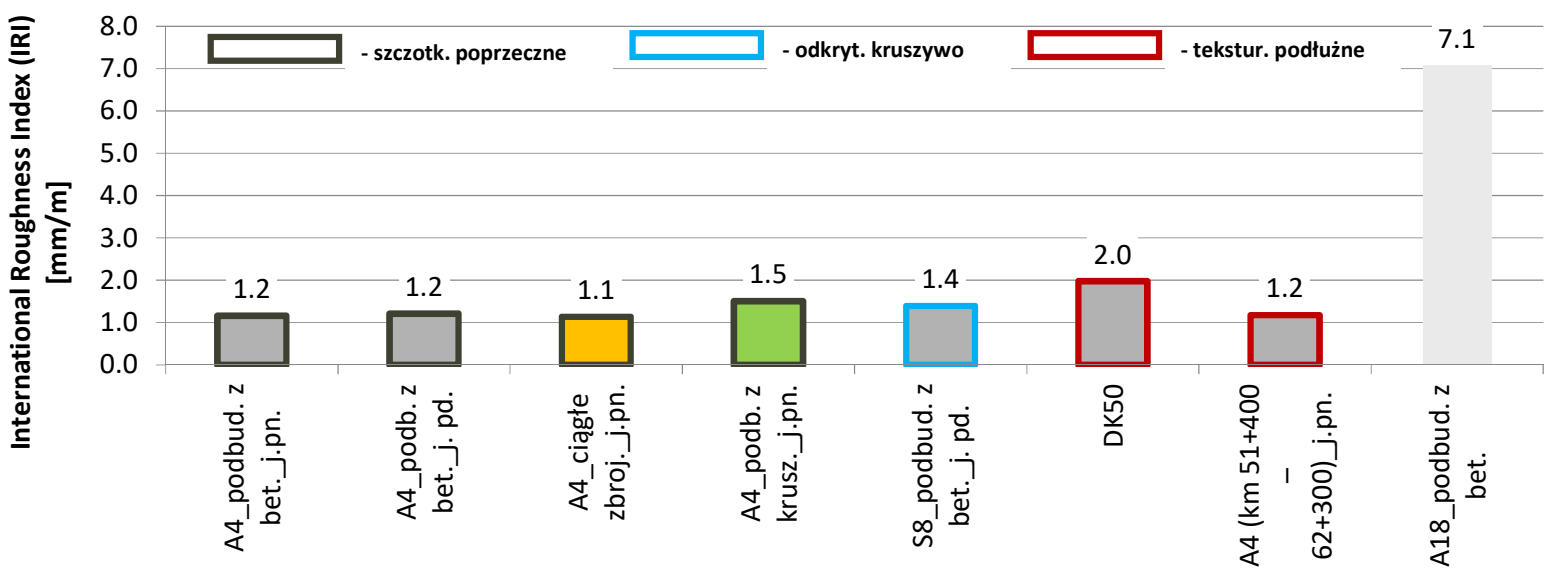

5. Comparative results of IRI index values

On the basis of a comparative analysis of different types of surface, it was found that the surface with continuous reinforcement has the lowest IRI value. Other surfaces also have relatively low values and are located in class A according to DSN, with the exception of the DK50 road (approaching the B class) and the exploited A18 road in class D. The structure on the aggregate foundation with IRI $=1.5$ is also slightly different. $\mathrm{mm} / \mathrm{m}$.In the case of the indicator responsible for texture (MPD), greater variation was found (Figure 6). However, it is not dictated by the type of construction, finishing technology and period of use.

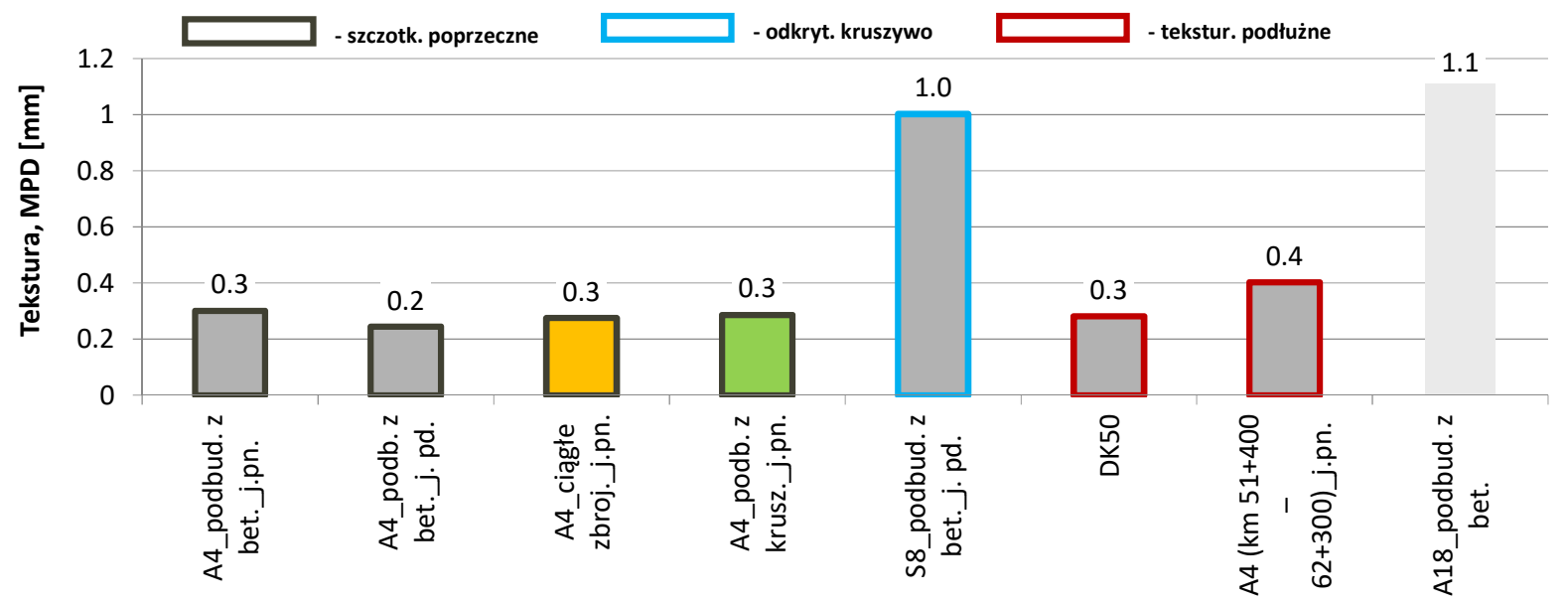

6. Comparative results of the MPD indicator values

It is worth noting that in one group of results there are surfaces of the A4 motorway with the texture of transverse brushing and the section of the A4 motorway $(\mathrm{km} 51+400-62$ +300 ) and DK50 made in longitudinal texturing (towed jute). In the second group, there are S8 surfaces made in the "discovered aggregate" technology. Large MPD values can be attributed to appropriate finishing technology and a relatively young, two-year service life. The smallest MPD values were obtained on over 15 years of A4, on which transverse 
brushing (about $0.2 \mathrm{~mm}$ ) was used on the surface. Slightly larger for a longitudinal texture (about $0.4 \mathrm{~mm}$ ). An exceptionally high texture index occurs on the old A18, which is dictated by the damaged surface structure and numerous crushed aggregate and grout grains.

At the same time, it should be noted that the tested surfaces have different delivery periods. A4 j. north - 2005, A4 j. south - 2000, S8 - 2015. Changes of the IRI index and MPD textures depending on the number of vehicles in service are shown in Figures 7 and 8, respectively (indicative results for A18 are included).

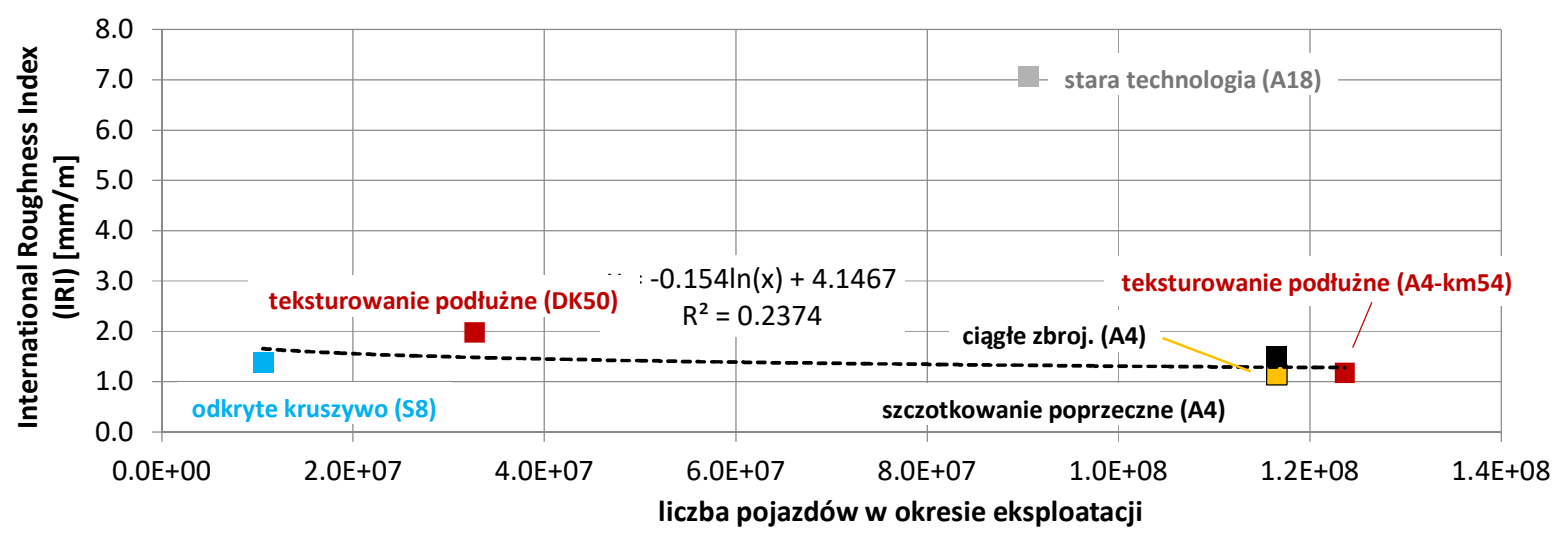

7. Changes in the IRI texture indicator depending on the number of vehicles in service

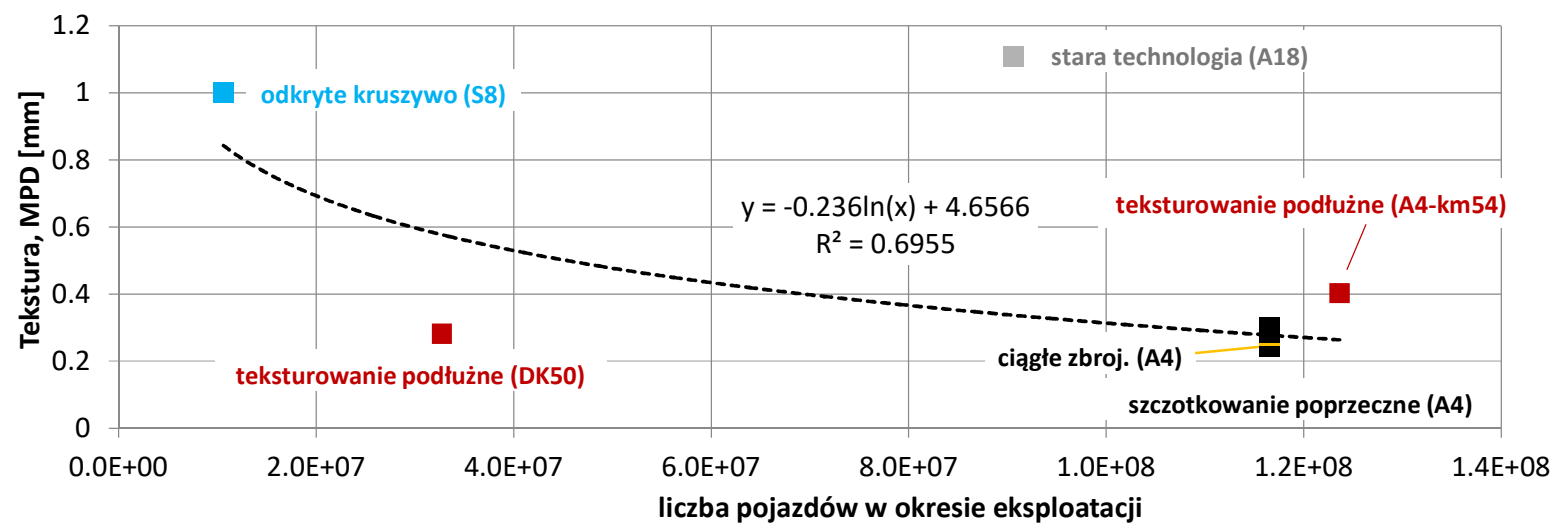

8. Changes in the MPD texture indicator depending on the number of vehicles in service

It is worth noting that much greater variation occurs for the change in the MPD indicator. Surfaces with a longer service life and/or finished in old texturing technology have a "worse" texture. On surfaces made with the "discovered aggregates" technology, almost four times higher MPD texture values are obtained compared to transverse brushing. The texture made in the technology of transverse brushing (from a dozen or so years ago) quickly deteriorated, definitely more than longitudinal texturing with the use of jute mat (20 years of operation), which shows a constant level of $0.3-0.4 \mathrm{~mm}$. Of course, the differences can also be associated with a significantly different traffic volume, an accuracy of execution, type of material (concrete, aggregates).

\section{Analysis of the sound level test results in the vehicle cabin}

Using the Sound Meter mobile application (Fig. 9), sound level measurements were carried out in the cab of a petrol vehicle (Opel Astra). Measurements were carried out on A4, S8, DK50 and A18 roads, on sections where equality and texture measurements were carried out. 


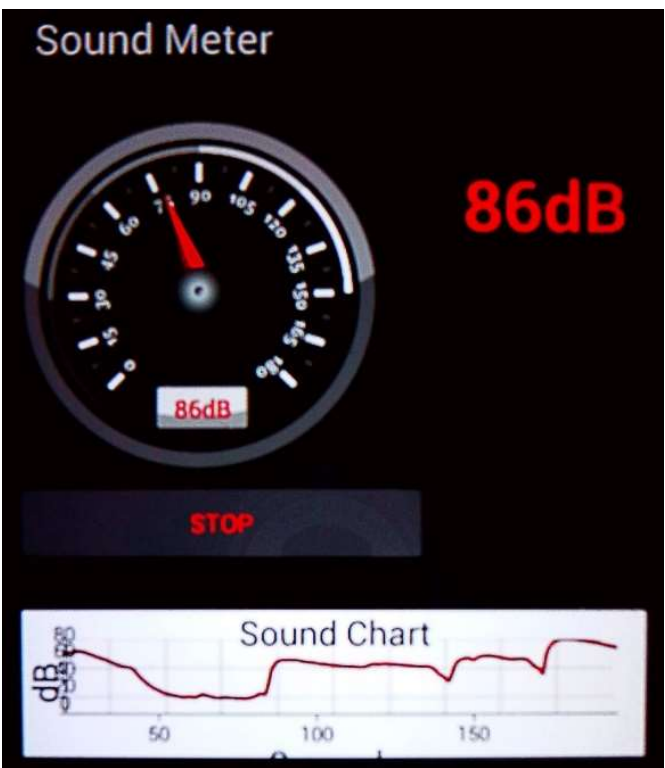

9. The Sound Meter mobile application

Fig. 10 presents the results of measurements of the sound level value in the vehicle cabin on the tested sections of the concrete road pavement.

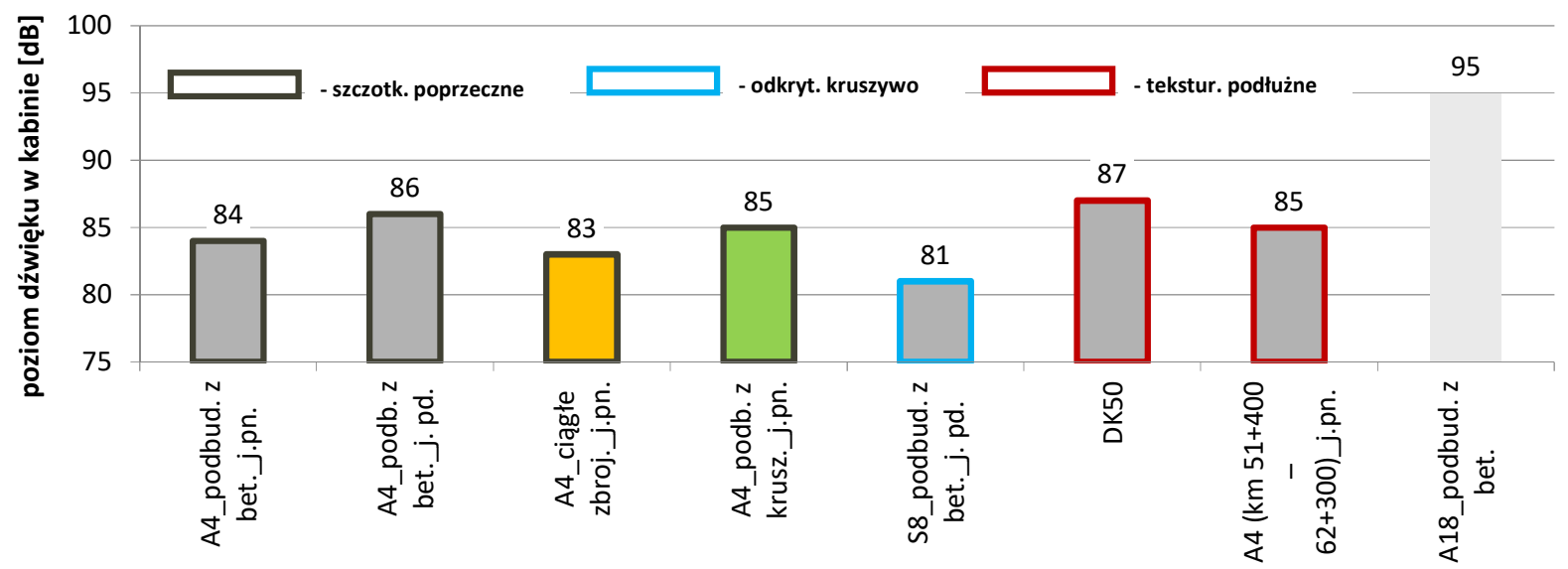

10. Comparative results of the sound level in the vehicle's cabin

The lowest sound levels were recorded on the surface with continuous reinforcement (A4) and on the surface of the S8 road made in the technology of the outdoor aggregate. The recorded sound levels of these surfaces are lower by about 3 - $6 \mathrm{~dB}$ compared to other surfaces that have dilatation and finish in the form of transverse or longitudinal brushing. Extremely high sound levels were recorded at A18 (95 dB). During the measurements, a vibration of various vehicle components was additionally audible. Sound measurements were carried out at a speed of $100 \mathrm{~km} / \mathrm{h}$. At higher speeds, the vehicle's air resistance had a decisive influence on noise.

Further analyzes were made on the comparison of the sound level measurement results against the IRI indicator (Figure 11) and the texture of the MPD (Figure 12). 


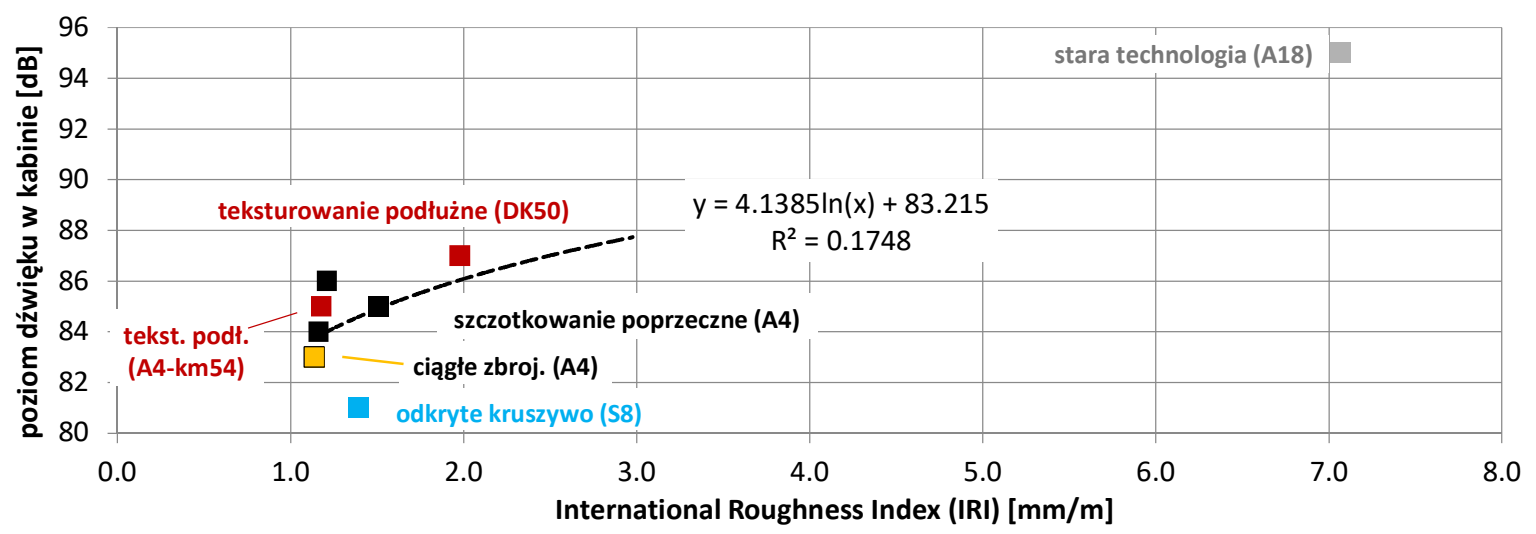

11. Correlation of the IRI indicator with the sound level in the vehicle's cabin

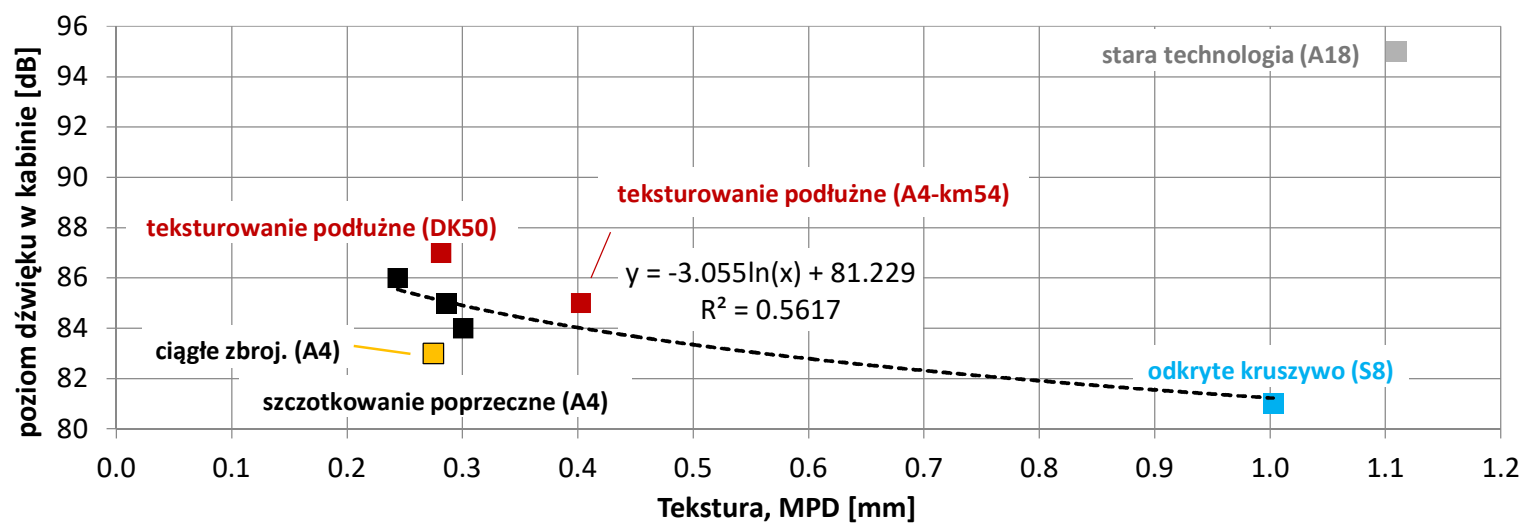

12. Correlation of the MPD indicator with the sound level in the vehicle cabin

Relatively good correlations were found (especially for the MPD texture) indicating a significant impact of both the type of construction and the finishing technology on the sound level. In the case of pavement with expansion joints, and particularly heavily worn out, the value of the IRI index exceeding the value of $2 \mathrm{~mm} / \mathrm{m}$ corresponding to class B according to DSN increases. If the MPD texture indicator increases, the sound level in the vehicle cabin decreases. Surfaces finished in the technology of the outdoor aggregate having the texture class A according to the DSN, are able to achieve a lower sound level by about $5 \mathrm{~dB}$ compared to the classic technologies of transverse brushing. Noteworthy is also the surface of continuous reinforcement, which, despite the use of transverse brushing and low-class texture (class D) also exhibits low sound levels.

A certain explanation of these relationships may be the correlation of the sound level in the vehicle cabin with the number of vehicles during the lifetime of the test surfaces (Figure 13). 


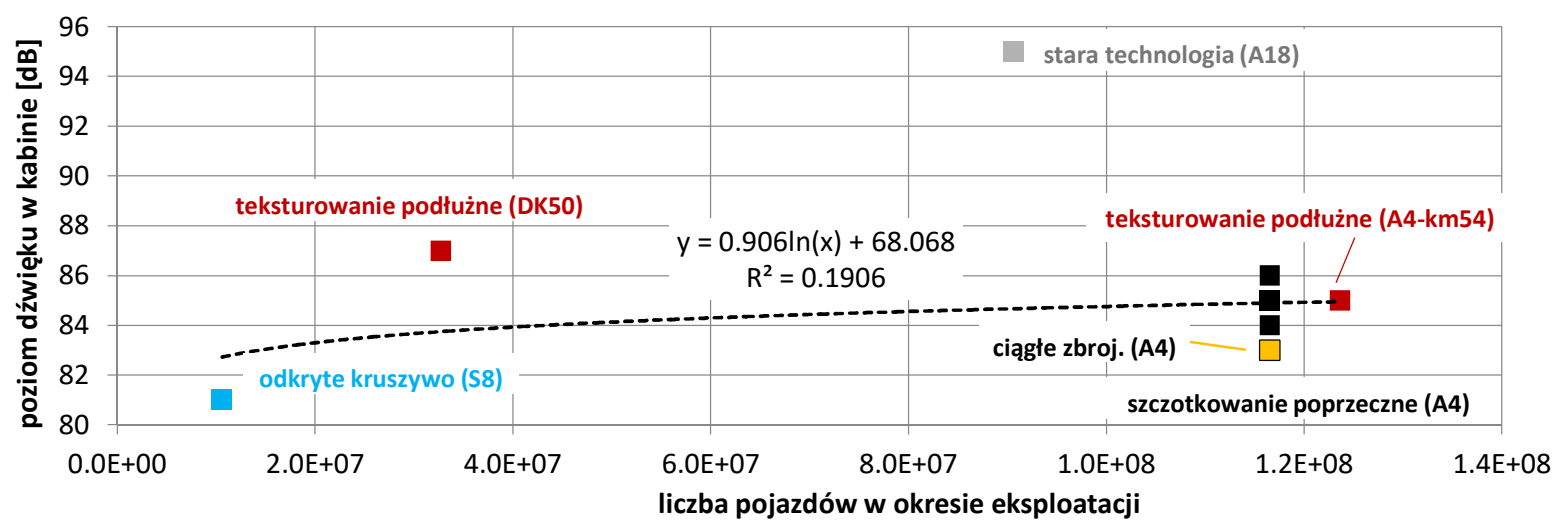

13. Correlation between the number of vehicles in service with the sound level in the vehicle cabin

Together with the increase in the number of vehicles (service life), an increase in the sound level by approximately $2 \mathrm{~dB} / 100$ million vehicles is expected.

\section{Summary}

Analysis of the results of research on the parameters of the surface exploitation features (equality, texture) showed that the heterogeneity in the measured values is related to the type of construction ("dilatation - non-dilatation") and finishing technology.

The analysis regarding the outflow of the construction type in the non-dilated technology indicated that the non-dilatation surfaces are characterized by better equality compared to the surfaces made in classical technology with gaps. The higher value of the IRI indicator (which proves the longitudinal unevenness) was obtained for the surface on the foundation of aggregate, while the largest on the depleted A18 motorway.

There was no apparent impact of the service life on the evenness of the tested concrete surfaces (except for A18). However, there is a good correlation between the MPD texture index and the number of vehicles in service. The best texture parameters for the relatively "young" S8 road surface made in the "discovered aggregate" technology have been found. The concrete surface on the A18 motorway is subject to a different assessment. The old, not used construction technology and long service life contributed to the significant damage in the gaps and irregularities in the longitudinal profile.

Based on the conducted research and analysis of results:

1. It is proposed in the equality and texture measurement procedure to take into account: the IRI index and the MPD indicator. These parameters well characterize the various types of pavement structures and classify them due to the way the upper surface is finished, also due to the different lifetime. They are also associated with the sound level recorded in the vehicle cabin.

2. It is stated that the "discovered aggregate" technology used in Poland, which has also proved successful in other European countries, provides good performance features on concrete surfaces and the lowest sound levels.

3. Concrete pavements with continuous reinforcement should be designed to handle very heavy traffic, because they are characterized by good equality regardless of the technology of finishing the upper surface and the service life.

4. At a later stage of the work, the authors will carry out analyzes of the sound level test results carried out with other methods (environmental noise measurement, OBSI (OnBoard Sound Intensity) method). 
5. Currently, "Grinding" and "Grooving" technologies are implemented in the country together with measurements of surface and noise surface features (route S8). The results of the work should give an answer in the field of using these technologies in the country.

Selected elements of this article were implemented as part of the RID (Road Noise Protection) project, which is co-financed by the National Center for Research and Development and the General Directorate of National Roads and Motorways.

\section{Source materials}

[1] American Concrete Pavement Association, Concrete Paving Technology: Constructing Smooth Concrete Pavements, Report RB006P, 2003

[2] ASTM E 1926 - 08 Standard Practice for Computing International Roughness Index of Roads from Longitudinal Profile Measurements

[3] ASTM E 2157 -02 Standard method for determining Mean Profile Depth using the Circular Track Meter. URL www.astm.org . Assessed 5/30/2009

[4] ASTM International, St andard Test Method for Measuring Pavement Macrotexture Depth using a Volumetric Technique, Specification E965-96, 2001

[5] Cable J.K., Wiegand P.: Surface Characteristics Next Generation Grooving and Grinding Iowa Test Site Construction, Final Report, National Concrete Pavement Technology Center, September, 2010

[6] Cackler E.T., et. al.: Concrete Pavement Surface Characteristics: Evaluation of Current Methods for Controlling Tire-Pavement Noise, Final Report of FHWA Cooperative Agreement DTFH61-01-X-00042, Project 15, 2006

[7] Cackler E.T.: Evaluation of U.S. and European Concrete Pavement Noise Reduction Methods, National Concrete Pavement Technology Center, Part 1, Task 2, of the ISUFHWA, July, 2006

[8] Development and Implementation of the Next Generation Concrete Surface, IGGA, ACPA, Report, 2016

[9] Diagnostyka stanu nawierzchni i jej elementów. Wytyczne stosowania, GDDKiA, Warszawa kwiecień, 2015

[10] Farnsworth E., Johnson M.: Reduction of Wet Pavement Accidents on Los Angeles Metropolitan Freeways, SAE Technical Paper 710574, 1971

[11] Federal Highway Administration, Surface Texture for Asphalt and Concrete Pavements, Technical Advisory T 5040.36, 17 June, 2005

[12] Ferragut T., Rasmussen R.O., Wiegand P., Mun E., Cackler E.T.: ISU-FHWA-ACPA Concrete Pavement Surface Characteristics Program Part 2: Preliminary Field Data Collection, National Concrete Pavement Technology Center Report DTFH61-01-X00042 (Project 15, Part 2), 2007

[13] Gardziejczyk W., Gierasimiuk P.: Influence of texturing method on tyre/road noise of cement concrete pavement. International Journal of Pavement Engineering, 2016, 1-16 (Article in Press)

[14] Gardziejczyk W.: „Cicha” nawierzchnia drogowa jako sposób na ograniczenie poziomu hałasu od ruchu samochodowego. Inżynieria Ekologiczna, 40, 2014, 65-73

[15] Gardziejczyk W:: Texture of road surfaces - methods of measurement, parameters evaluation and its influence on the tire/road noise. Roads and Bridges - Drogi i Mosty, 1, 2, 2002, 5-29

[16] Grogg Max G., Smith Kurt D.: PCC Pavement Smoothness: Characteristics and Best Practices for Construction, Report FHWA-IF-02-025, October, 2001 
[17] Guntert \& Zimmerman Const. Div., Inc.: Various Engineering Drawings, 4/20/2008.30. Minnesota Department of Transportation, Minnesota's Astro-Turf Drag Technique Texturing Concrete Pavements, 2008

[18] Hall J.W., Smith K. L.: Littleton Texturing of Concrete Pavements, NCHRP report 634

[19] Herman L., McAvoy D., Richardson W.: Effectiveness of Noise Barriers Installed Adjacent to Transverse Grooved Concrete Pavements. Federal Highway Administration, Job Number 134365, October 16, 2009

[20] Hibbs O., Larson R.: Tire Pavement Noise and Safety Performance. PCC Surface Texture Technical Working Group, FHWA-SA-96-068, May, 1996

[21] Karamihas S.M., Gillespie T.D., Perera R.W., Kohn S.D.: Diurnal changes in profile of eleven jointed PCC pavement. Proceedings of $7^{\text {th }}$ International Conference on Concrete Pavements, Orlando, FL., 2001

[22] Kowalski K.J., Bańkowski W., Król J.B., Gajewski M., Horodecka R., Świeżewski P.: Selection of quiet pavement technology for Polish climate conditions on the example of CiDRO project - Transportation Research Procedia 14, 2016, 2724-2733

[23] Mioduszewski P.: Przegląd hałaśliwości nawierzchni drogowych w Polsce i w innych krajach Unii Europejskiej. Metody ochrony przed hałasem. Teoria i praktyka, 1, 2013, $159-173$

[24] Noise and Texture on PCC Pavements - Results of a Multi-State Study, Report Number WI/SPR-08-99, Wisconsin Department of Transportation, June, 2000

[25] Pitre J.G.: Improving the sound absorbing capacity of portland cement concrete pavements using recycled materials. Thesis, Bachelor of Science, University of New Hampshire, 2000

[26] PN-EN ISO 13473-1:2005E, Charakterystyka struktury nawierzchni przy użyciu profili powierzchniowych - Część 1: Określenie średniego profilu głębokości

[27] Rasmussen, R., Sohaney R., Fick G., Cackler E.T.: How to Design and Construct Quieter Concrete Pavements. 10th International Conference on Concrete Pavements, July 8-12, 2012, Quebec

[28] Rozporządzenia Ministra Infrastruktury z dnia 16 stycznia 2002 r. w sprawie przepisów techniczno-budowlanych dotyczących autostrad płatnych

[29] Scofield L.: Transportation Noise and Concrete Pavements, Using Quiet Concrete Pavements as the Noise Solution, ACPA, 2009

[30] Sommer H.: Optimierung der Lärmmindernden Waschbeton-oberfläche (Optimisation of Noise Reducing Exposed Aggregate Concrete Surfaces), Vienna (Austria): State Ministry for Economic Affairs, File 447, 1995 